\title{
An Alternative Reaction Pathway for Iridium-Catalyzed Water Oxidation Driven by Cerium Ammonium Nitrate (CAN)
}

\author{
Alberto Bucci, ${ }^{\dagger}$ Gabriel Menendez Rodriguez, ${ }^{\dagger}$ Gianfranco Bellachioma, ${ }^{\dagger}$ Cristiano Zuccaccia, ${ }^{\dagger}$ \\ Albert Poater, Luigi Cavallo, ${ }^{*}, \S$ and Alceo Macchioni ${ }^{*}{ }^{\dagger}$ \\ ${ }^{\dagger}$ Department of Chemistry, Biology and Biotechnology, University of Perugia and CIRCC, Via Elce di sotto, 8, I-06123 Perugia, Italy \\ ${ }^{\ddagger}$ Institut de Química Computacional i Catàlisi and Departament de Química, Universitat de Girona, Campus Montilivi, 17071 Girona, \\ Catalonia, Spain \\ ${ }^{\S}$ KAUST Catalysis Center (KCC), King Abdullah University of Science and Technology (KAUST), Thuwal 23955-6900, Saudi \\ Arabia
}

Supporting Information

ABSTRACT: The generation of solar fuels by means of a photosynthetic apparatus strongly relies on the development of an efficient water oxidation catalyst (WOC). Cerium ammonium nitrate (CAN) is the most commonly used sacrificial oxidant to explore the potentiality of WOCs. It is usually assumed that CAN has the unique role to oxidatively energize WOCs, making them capable to offer a low-energy reaction pathway to transform $\mathrm{H}_{2} \mathrm{O}$ to $\mathrm{O}_{2}$. Herein, we show that CAN might have a much more relevant and direct role in $\mathrm{WO}$, mainly related to the capture and liberation of $\mathrm{O}-\mathrm{O}$-containing molecular moieties.
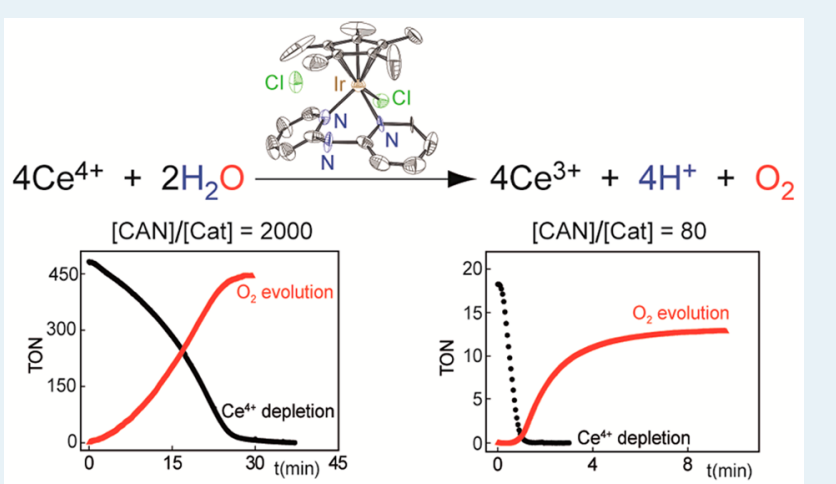

KEYWORDS: water oxidation, iridium complexes, cerium ammonium nitrate, reaction mechanism, DFT calculations

W ater oxidation (WO) to molecular oxygen is one of the most important chemical reactions, because the protons and electrons that are liberated can be exploited to produce solar fuels. ${ }^{1,2}$ Because of kinetic concerns, a catalyst $(\mathrm{C})^{3,4}$ is necessary to lower and level, as much as possible, the energetics of the oxidative steps. Unless $\mathrm{C}$ acts also as photosensitizer and electron/hole separating agent, whatever the nature of $\mathrm{C}$ is, WOC must be preliminarily "energized" by an oxidant in order to make it capable of promoting WO. In nature, this occurs through the interaction of the oxygen-evolving complex with the radical tyrosine (generated from $\mathrm{P} 60^{+}$and imidazole of His 190 via a PCET process)..$^{5}$ In a man-made apparatus, oxidation occurs via the interaction of WOC with either a properly selected chemical oxidant, ${ }^{6}$ an anode (photoelectrochemical catalysis), ${ }^{7}$ or a photo-oxidant derived from the interaction of light with a photosensitizer (photocatalysis). ${ }^{8}$ As a consequence, the knowledge of the WOC/oxidant interaction mechanism is of primary importance; however, rather surprisingly, such an issue is rarely addressed ${ }^{9-15}$ in the astonishingly increasing number of papers that involve WOCs.

During our attempts ${ }^{16}$ to develop new and better-performing WOCs based on iridium, ${ }^{17}$ we decided to explore the potential of an organometallic compound formally derived from the insertion of a $-\mathrm{NH}$ - electron-donating bridge between the two pyridine rings of the previously reported $[\mathrm{Cp} * \mathrm{Ir}(\mathrm{bpy}) \mathrm{Cl}] \mathrm{Cl}$ WOC $\left(1 ;\right.$ bpy $=2,2^{\prime}$-bipyridine $($ see Scheme 1$\left.)\right) .{ }^{16 a}$ The rationale is 2 -fold and aims at favoring the oxidative steps and assisting removal of protons from a water molecule coordinated at the Ir center.

Herein, we show that the new $\left[\mathrm{Cp}^{*} \operatorname{Ir}(\mathrm{dpa}) \mathrm{Cl}\right] \mathrm{Cl}$ WOC (2; $\mathrm{dpa}=2,2^{\prime}$-dipyridylamine $($ Scheme 1$\left.)\right)$ is indeed much more

Scheme 1. (Left) Sketch of WOCs 1 and 2; (Right) ORTEP View of Complex $2^{a}$
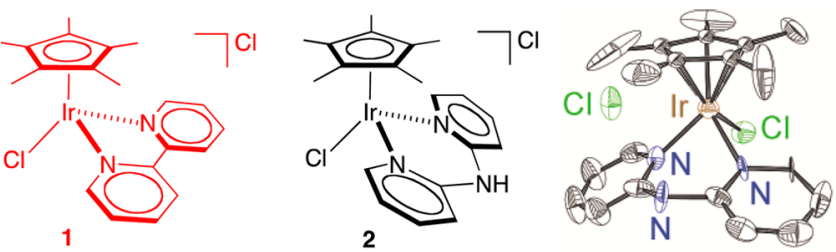

${ }^{a}$ Ellipsoids are drawn at the $50 \%$ probability level. Selected bond distances $(\AA): \mathrm{Ir}-\mathrm{N} 1=2.121(12), \mathrm{Ir}-\mathrm{N} 3=2.133(12), \mathrm{Ir}-\mathrm{Cl} 1=$ 2.392(4), Ir-Cp* $=1.788$. Selected bond angles (deg): N1-Ir-N3 = 82.96(4), $\mathrm{N} 1-\mathrm{Ir}-\mathrm{Cl} 1=88.8(3), \mathrm{N} 3-\mathrm{Ir}-\mathrm{Cl}=87.9(3), \mathrm{Cp} *-\mathrm{Ir}-\mathrm{N} 1=$ 130.3, $\mathrm{Cp}^{*}-\mathrm{Ir}-\mathrm{N} 3=125.5, \mathrm{Cp} *-\mathrm{Ir}-\mathrm{Cl}=127.2$. $\mathrm{Cp}^{*}$ is the centroid of the C11, C12, C13, C14, and C15 atoms.

Received: May 12, 2016

Revised: June 9, 2016

Published: June 10, 2016 
active than 1 when catalysis is driven by cerium ammonium nitrate (CAN); however, more importantly, it exhibits a peculiar catalytic behavior when a relatively small excess (80320 equiv) of CAN is used. Particularly, CAN is always consumed faster than $\mathrm{O}_{2}$ evolution, and, in extreme cases, it is almost completely consumed before $\mathrm{O}_{2}$ begins to be formed. An in-depth kinetic investigation, paralleled by quantum mechanical calculations, led to the suggestion of an alternative reaction pathway in which, after CAN-driven and iridiumcatalyzed $\mathrm{O}-\mathrm{O}$ bond formation, $\mathrm{O}_{2}$ is slowly liberated through an uncatalyzed process, likely from a cerium intermediate species.

Complex 2 was synthesized by the reaction of the dimeric precursor $\left[\mathrm{Cp}^{*} \mathrm{IrCl}_{2}\right]_{2}$ with 2 equiv of dpa in methylene chloride at room temperature (see the Supporting Information (SI)). 2 was completely characterized in solution via multinuclear and multidimensional NMR spectroscopy and in the solid state by X-ray crystallography (see Scheme 1 and the SI).

Complexes 1 and 2 were tested as WOCs using CAN as a sacrificial oxidant. It was found that the catalytic behaviors of 1 and $\mathbf{2}$ are markedly different. In particular, the activity of complex $\mathbf{2}$ is strongly dependent on the molar ratio $R$ between CAN and catalyst $(R=[\mathrm{CAN}] /[\mathrm{C}])$, whereas that of $\mathbf{1}$ is very insensitive to such a ratio (Figure 1, left). In experiments in
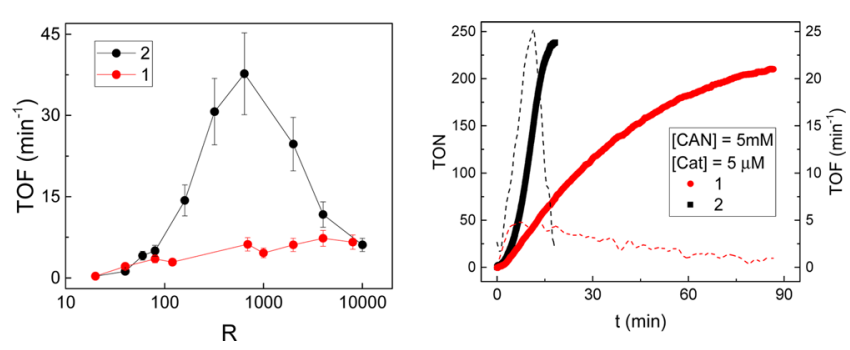

Figure 1. (Left) Trends of TOF versus the molar ratio $R$ between CAN and catalyst $(R=[\mathrm{CAN}] /[\mathrm{C}])$ for WOCs $\mathbf{1}$ and $\mathbf{2}$ obtained by means of differential manometry ( $R$ scale is logarithmic). (Right) Comparison of TON (continuous line) and TOF (dashed line) vs $t$ of WOCs 1 and 2 under exactly the same experimental conditions.

which $[\mathrm{CAN}]=10 \mathrm{mM}$, the turnover frequency $(\mathrm{TOF})$ of 2 reaches a maximum of $38 \mathrm{~min}^{-1}$ when $[\mathrm{C}]=15.6 \mu \mathrm{M}$ and $\mathrm{R}=$ 640 (Figure 1, left). Furthermore, the trends of oxygen evolution with 2 show an increase of activity at the end of the run. For instance, when $[\mathrm{CAN}]=5 \mathrm{mM}$ and $[\mathrm{C}]=5 \mu \mathrm{M}(R=$ 1000), the TOF vs $t$ trends indicate that, initially, 1 and 2 have a similar TOF but that of 2 increases up to a maximum value $\left(25 \mathrm{~min}^{-1}\right)$, close to the end of the catalytic run, more than 6 times higher than that of $1\left(4 \mathrm{~min}^{-1}\right)$, which remains substantially constant until the end of catalysis (Figure 1, right). Previous studies on the oxidative transformations of IrCp* precursors for WO clearly indicate that many active species can be generated, potentially having different catalytic activity. ${ }^{166,18-20}$ Furthermore, very recently, Reek and coworkers showed that the nature of the ancillary ligand(s) attached to the $\mathrm{IrCp}$ * moiety strongly affects the activation and catalysis of the resulting complexes. ${ }^{21} \mathrm{H}$ NMR experiments in which 1 and 2 were reacted with 80 equiv of CAN (10 mM) revealed a higher tendency of the latter to undergo $\mathrm{Cp}^{*}$ oxidative transformation, as judged from the amount of acid acetic formed (41\% for 2 and $25 \%$ for 1 ; see Figures S9 and $\mathrm{S} 10$ in the SI). The introduction of a peripheral $-\mathrm{NH}$ moiety might be responsible for the easier oxidative degradation of $\mathbf{2}$, generating more active sites, in analogy with that elegantly demonstrated by Fukuzumi for 4,4'-OH-disubstituted bpy. ${ }^{22}$

The kinetics of WO with $\mathbf{1}$ and $\mathbf{2}$ was studied more in detail, approaching the problem by independently following the disappearance of CAN by ultraviolet-visible light (UV-vis) spectroscopy, evaluated at $390 \mathrm{~nm}$, and the evolution of $\mathrm{O}_{2}$ by manometry and Clark electrode. All experiments were performed at $[\mathrm{CAN}]=5-10 \mathrm{mM}$, whereas $[\mathrm{C}]$ was increased to reach the desired low $R$ values. Fixing the concentration of CAN at such high values ensured that the amount of evolved oxygen was accurately detected.

A peculiar behavior was found for both catalysts at low $R$ values (80-320), where the rate of CAN consumption was always higher than that of $\mathrm{O}_{2}$ evolution for both WOCs, even though this phenomenon is much more accentuated for 2 (compare Figures S12-S14 in the SI with Figures S15-S17 in the SI). As an example, for the latter, CAN consumption is perfectly accompanied by $\mathrm{O}_{2}$ evolution when $R=2000$ (Figure 2 , left), with the two trends crossing at almost exactly half of
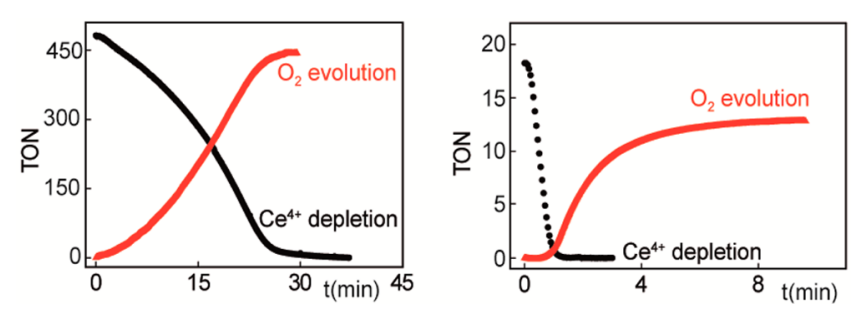

Figure 2. Kinetic trends of CAN depletion and $\mathrm{O}_{2}$ evolution for WOC 2, measured by UV-vis and differential manometer when $R=2000$ (left) and $R=80$ (right) $([\mathrm{CAN}]=10 \mathrm{mM})$.

the expected cycles (250); instead, when $R=80$, all CAN is consumed within $<2 \mathrm{~min}$, whereas $\mathrm{O}_{2}$ evolution starts just slightly before $2 \mathrm{~min}$, reaching a plateau after $\sim 8 \mathrm{~min}$ (Figure 2, right). To verify that the lower rate of $\mathrm{O}_{2}$ production was correctly evaluated by differential manometry, experiments were repeated, following $\mathrm{O}_{2}$ production by Clark electrode in solution; exactly the same results were obtained in terms of induction time and rate of $\mathrm{O}_{2}$ evolution (Figure $\mathrm{S} 18$ in the SI). A similar marked difference in the velocity of CAN consumption, with respect to $\mathrm{O}_{2}$ evolution, was observed in all runs of multiple addition experiments (Figure S19 in the SI), even if the overlapping between the two trends slightly increases as the number of runs increases.

Although part of CAN equivalents was surely consumed for oxidatively transforming the precatalysts, this cannot account for all consumption of CAN; otherwise, no oxygen evolution should be observed. Furthermore, the discrepancy between CAN consumption and $\mathrm{O}_{2}$ production should be much more limited, or absent, in runs successive to the first one, and this is not the case (Figure S19).

In order to explore the generality of higher rate for CAN consumption, with respect to $\mathrm{O}_{2}$ evolution, we performed analogous kinetic experiments also for $[\mathrm{Cp} * \operatorname{Ir}($ bzpy $)$ $\left.\left(\mathrm{NO}_{3}\right)\right] \mathrm{NO}_{3}$ (3) and $\left[\mathrm{Cp} * \operatorname{Ir}\left(\mathrm{H}_{2} \mathrm{O}\right)_{3}\right]\left(\mathrm{NO}_{3}\right)_{2}$ (4), two wellestablished WOCs, and $\mathrm{IrO}_{2}(\mathbf{5})$, the benchmark heterogeneous WOC. It was found that CAN depletion was always faster than $\mathrm{O}_{2}$ evolution, even if for WOCs 1, 3, and 5, which were the slowest catalysts under our conditions, the phenomenon was less accentuated (see Figures S24-S33 in the SI). Also, for 4, experiments of multiple additions of CAN show that CAN consumption was complete before $\mathrm{O}_{2}$ 
production for cycles successive to the first one, analogous to that observed for 2 (Figure S34 in the SI). Interestingly, a comparison of the two multiple-run experiments for $\mathbf{2}$ and $\mathbf{4}$ shows that CAN consumption is much faster for the latter, whereas $\mathrm{O}_{2}$ evolution substantially occurs with the same rate in all runs (see Figure S35 in the SI).

The observations reported above clearly indicate the formation of an intermediate (X), which accumulates in between $\mathrm{Ce}^{\mathrm{IV}}$ and $\mathrm{O}_{2}$. For those reasons, we treated our data using the simplest kinetic model, typical of a three-species consecutive reaction, involving the reaction of $\mathrm{Ce}^{\mathrm{IV}}$ to afford $\mathrm{X}$ $\left(k_{1}{ }^{\text {obs }}\right)$, followed by the liberation of $\mathrm{O}_{2}$ from $\mathrm{X}\left(k_{2}{ }^{\text {obs }}\right)$ (SI). Clearly, $\mathrm{C}$ might intervene in each reaction; consequently,

$$
k_{1}^{\mathrm{obs}}=k_{1}[\mathrm{C}]^{n}
$$

and

$$
k_{2}^{\mathrm{obs}}=k_{2}[\mathrm{C}]^{m}
$$

where $n$ and $m$ are the reaction orders of $\mathrm{C}$, respectively. $k_{1}{ }^{\text {obs }}$ and $k_{2}{ }^{\text {obs }}$ were derived fitting the kinetic trends, with

$$
\left[\mathrm{Ce}^{\mathrm{IV}}\right]=\left[\mathrm{Ce}^{\mathrm{IV}}\right]_{0}-4 k_{1}^{\mathrm{obs}} t
$$

and

$$
\left[\mathrm{O}_{2}\right]=\frac{\left[\mathrm{Ce}^{\mathrm{IV}}\right]_{0}}{4}\left\{1-\exp \left(-k_{2}^{\mathrm{obs}} t\right)\right\}
$$

respectively (Figures S35 and S36 in the SI). $k_{1}{ }^{\text {obs }}$ and $k_{2}{ }^{\text {obs }}$ data for $\mathbf{1}$ and $\mathbf{2}$ and other WOCs are reported in the SI. From the dependence of $k_{1}{ }^{\text {obs }}$ and $k_{2}{ }^{\text {obs }}$ on [C], the orders $n$ and $m$ on the catalyst were calculated. Interestingly, it was found that $n \approx 1$ and $m \approx 0$ for all catalysts, indicating that the role of catalyst is exerted only in the reaction leading to $\mathrm{X}$, which is the fastest under our conditions of small $R$ values, whereas evolution of $\mathrm{O}_{2}$ from $\mathrm{X}$ seems to be an uncatalyzed reaction determining the global reaction rate. Consistently, when $[\mathrm{C}]$ is decreased, down to the typical values exploited in standard catalytic experiments (1-5 $\mu \mathrm{M})$, the depletion of $\mathrm{Ce}^{\mathrm{IV}}$ becomes the rate-determining step and the trends of $\mathrm{Ce}^{\mathrm{IV}}$ consumption and $\mathrm{O}_{2}$ evolution are perfectly coherent and cross at exactly the midpoint (Figure 2).

As far as the nature of $\mathrm{X}$ is concerned, several scenarios might be envisioned, considering that $\mathrm{X}$ must have the capability of releasing $\mathrm{O}_{2}$. As stated above, it is unlikely that an oxidized form of iridium WOCs uniquely constitutes $\mathrm{X}$, also because the maximum turnover number (TON) reachable in cases such as that reported in Figure 2 would be 1 .

Another possibility is that $\mathrm{X}=\mathrm{H}_{2} \mathrm{O}_{2}$. However, also this hypothesis is unlikely for several reasons. First of all, it is wellknown that CAN quickly reacts with $\mathrm{H}_{2} \mathrm{O}_{2}$, thus making its accumulation during WO reactions improbable. ${ }^{23}$ Consistently, we performed some kinetic experiments between CAN (10 $\mathrm{mM})$ and $\mathrm{H}_{2} \mathrm{O}_{2}(5 \mathrm{mM})$ under conditions analogous to those used for WO. Indeed, we found that reaction is much faster than WO catalysis $\left(k_{\mathrm{CAN}}^{\mathrm{obs}}=99.5 \mathrm{mM} / \mathrm{min}\right.$ and $k_{\mathrm{O}_{2}}^{\mathrm{obs}}=73.0 \mathrm{mM}$ / min; see Figure S38 in the SI). Second, we performed some kinetic experiments of $\mathrm{H}_{2} \mathrm{O}_{2}$ disproportionation in the presence of WOC and $\mathrm{Ce}^{\mathrm{III}}$, under the absurd assumption that all CAN is consumed to quantitatively generate $\mathrm{H}_{2} \mathrm{O}_{2}$ (Figure $\mathrm{S} 39$ in the $\mathrm{SI}$ ). The reaction did not occur throughout the time scale of WO reaction. These experiments exclude the possibility that $\mathrm{X}$ $=\mathrm{H}_{2} \mathrm{O}_{2}$.
A hypothesis that agrees with all observations is that $\mathrm{X}$ is a Ce species, containing an $\mathrm{O}-\mathrm{O}$ moiety, capable of releasing $\mathrm{O}_{2}$ without the intervention of the catalyst. The formation of such a species is a viable possibility, since polynuclear cerium compounds bearing both $\mu$ - and $\mu-\eta^{2}: \eta^{2}$-peroxo bridging ${ }^{24-27}$ as well as monohydroperoxide species of cerium ${ }^{28,29}$ are welldocumented in the literature. In this respect, very recently, Tsurugi and Mashima showed that a stable and wellcharacterized $\mu-\eta^{2}: \eta^{2}$-peroxo bridged-Ce(IV) dimer easily forms from the reaction of a monomeric $\mathrm{Ce}$ (III) precursor and dissolved $\mathrm{O}_{2}{ }^{30}$ Furthermore, the affinity of ceria for reactive oxygen species (ROS) is very well-known; ${ }^{31}$ as a matter of fact, it is frequently used as free-radical scavenger with important applications in medicine, biology, energy, and catalysis. $^{31}$

In order to shed some light on the nature of $\mathrm{X}$, multiple run UV-vis experiments with $2(R=80)$ were carefully analyzed. A band at $570 \mathrm{~nm}$ was found to have the correct kinetic features of an intermediate: it growths during CAN depletion, with a similar rate constant, reaching a maximum of intensity when $\mathrm{CAN}$ is finished, and disappears during $\mathrm{O}_{2}$ evolution, again with a similar rate constant, in all runs (Figure S19). Although a similar band has been observed previously and has been assigned to molecular $\operatorname{Ir}(\mathrm{IV})^{32}$ and clusters/nanoparticles of $\mathrm{Ir},{ }^{33}$ it is also consistent with the formation of a Ce(IV) dimer analogous to that reported by Tsurugi and Mashima, ${ }^{30}$ which shows a band at $575 \mathrm{~nm}$. None of two possibilities can be proved or discarded with certainty; nevertheless, the latter appears to be slightly preferable, because it better agrees with the nonsynchronous CAN depletion and uncatalyzed $\mathrm{O}_{2}$ evolution. This would mean that, at low $R$ values, $\mathrm{Ce}^{\mathrm{IV}}$ does not have the necessary potential to induce the last oxidative step $^{34}$ and, during such an attempt, likely occurring through an inner sphere mechanism, a moiety containing the preformed $\mathrm{O}-\mathrm{O}$ unit is transferred from Ir to a Ce dimer (or cluster ${ }^{35}$ ), which evolves $\mathrm{O}_{2}$ without the intervention of Ir. Consistently, such behavior is expected and found to be more accentuated for catalysts having a higher tendency to enter the catalytic cycle as $\mathbf{2}$ and $\mathbf{4}$ for which the real value of $R$ coincides with the nominal one. ${ }^{34}$ It is important to outline that no hypothesis has been done on the nature of the Ir active species that can consequently be just the molecular precursor, a still molecular oxidized derivative, or even an aggregate of nanometric dimensions. $^{22,33,36}$

With the aim of rationalizing the kinetic results, we performed DFT calculations for $2,{ }^{37}$ focusing on $\mathrm{O}-\mathrm{O}$ bond formation involving both $\mathrm{Ir}$ and Ce species. Considering that the mechanism of $\mathrm{O}-\mathrm{O}$ bond formation in $\mathrm{Ir}$ organometallic WOCs and the structure of CAN in solution are still a matter of debate, the only scope of this section is to show that a lowenergy pathway for $\mathrm{O}-\mathrm{O}$ bond formation involving $\mathrm{Ce}$ species is viable. To limit the number of assumptions, we considered species already proposed in the literature by Sakai and others, ${ }^{9,11,12}$ namely $\mathrm{L}_{n} \mathrm{Ir}^{\mathrm{IV}}-\mathrm{O} \bullet$ and $\left[\mathrm{Ce}^{\mathrm{IV}}\left(\mathrm{NO}_{3}\right)_{n} \mathrm{OH}\right]^{4-n-1}(n$ $=3$ and 4). Furthermore, pathways assisted by external water molecules were considered. ${ }^{38}$ Before discussing the potential role of $\mathrm{Ce}$ in $\mathrm{O}-\mathrm{O}$ bond formation, we revisited the wellaccepted water nucleophilic attack ${ }^{39}$ and interaction between two $\mathrm{M}-\mathrm{O}$ moieties mechanisms.

$\mathrm{O}-\mathrm{O}$ bond formation by direct reaction between two $\mathrm{L}_{n} \mathrm{Ir}^{\mathrm{IV}}-\mathrm{O} \bullet$ moieties $(\mathrm{SI})^{40}$ is exergonic and has an activation barrier of $22.4 \mathrm{kcal} / \mathrm{mol}$, while external water nucleophilic attack $^{38}$ at the $\mathrm{L}_{n} \mathrm{Ir}^{\mathrm{IV}}-\mathrm{O} \bullet$ moiety has an activation barrier of 
$25.9 \mathrm{kcal} / \mathrm{mol}^{41}$ This is $3.5 \mathrm{kcal} / \mathrm{mol}$ higher than direct interaction between two $\mathrm{L}_{n} \mathrm{Ir}^{\mathrm{IV}}-\mathrm{O} \bullet$ moieties, with the additional drawback that it is endergonic by $7.5 \mathrm{kcal} / \mathrm{mol}$.

At this point, we investigated the potential role of $\mathrm{Ce}$ species in $\mathrm{O}-\mathrm{O}$ bond formation. Direct interaction of $\mathrm{L}_{n} \mathrm{Ir}^{\mathrm{IV}}-\mathrm{O} \bullet$ with $\left[\mathrm{Ce}^{\mathrm{IV}}\left(\mathrm{NO}_{3}\right)_{n} \mathrm{OH}\right]^{4-\mathrm{n}-1}(n=3,4)$, reduces the energy barrier for $\mathrm{O}-\mathrm{O}$ bond formation to $\sim 16-20 \mathrm{kcal} / \mathrm{mol}$. The transition state is characterized by an $\mathrm{O}-\mathrm{O}$ distance of $1.75 \AA$ and by an incipient interaction between the $\mathrm{Ce}$ atom and the $\mathrm{O}$ atom of the Ir moiety. The final product presents a strong interaction between $\mathrm{Ce}$ and the two $\mathrm{O}$ atoms of the formed $\mathrm{O}-\mathrm{O}$ bond (SI). Interestingly, the reaction pathway with $\left[\mathrm{Ce}^{\mathrm{IV}}\left(\mathrm{NO}_{3}\right)_{n} \mathrm{OH}\right]^{4-n-1}$ assisting nucleophilic attack of a water molecule to $\mathrm{L}_{n} \mathrm{Ir}^{\mathrm{IV}}-\mathrm{O} \bullet$ (Figure 3 ) has an even lower barrier
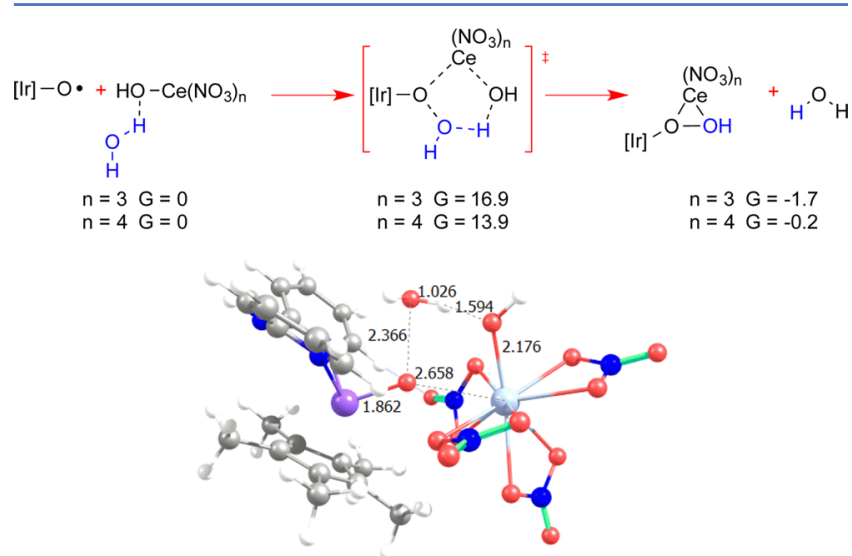

Figure 3. Schematic representation of $\mathrm{O}-\mathrm{O}$ bond formation via nucleophilic attack of a water molecule to a $\mathrm{L}_{n} \mathrm{Ir}^{\mathrm{IV}}-\mathrm{O} \bullet$ moiety, assisted by $\left[\mathrm{Ce}^{\mathrm{IV}}\left(\mathrm{NO}_{3}\right)_{4} \mathrm{OH}\right]^{-1}$ (top). Geometry of transition state for $\mathrm{L}_{n} \mathrm{Ir}^{\mathrm{IV}}-$ $\mathrm{O} \bullet+\left[\mathrm{Ce}^{\mathrm{IV}}\left(\mathrm{NO}_{3}\right)_{4} \mathrm{OH}\right]^{-1}$ (bottom, distances given in $\AA$ ).

(14-16 kcal/mol, clearly lower than any barrier not assisted by $\mathrm{Ce})$. It also has the advantage of being exergonic, thus driving thermodynamically $\mathrm{O}-\mathrm{O}$ bond formation. The transition state geometry of Figure 3 illuminates the dual role of the $\mathrm{Ce}-\mathrm{OH}$ moiety, with the $\mathrm{Ce}$ atom interacting with the $\mathrm{O}$ atom of $\mathrm{L}_{n} \mathrm{Ir}^{\mathrm{IV}}-\mathrm{O} \bullet$, rendering it more electrophilic, and the $\mathrm{OH}$ moiety acting as proton acceptor from the water molecule performing the nucleophilic attack.

In conclusion, the kinetic results herein reported strongly suggest an alternative mechanism for WO driven by CAN in which, after an Ir-catalyzed phase, leading to the formation of a $\mathrm{O}-\mathrm{O}$ bond containing moiety, the latter is transferred from $\mathrm{Ir}$ to an intermediate $\mathrm{Ce}$ species that slowly liberates $\mathrm{O}_{2}$ without the intervention of the catalyst. Density functional theory (DFT) calculations show that CAN has a remarkable positive effect in the critical step of $\mathrm{O}-\mathrm{O}$ bond formation. The proposed mechanism, deduced by investigating Ir WOCs but, in principle, of rather general validity, evidence once more, from an unprecedented perspective, the critical importance of multimetallic synergistic interactions in WOCs.

\section{ASSOCIATED CONTENT}

\section{S Supporting Information}

The Supporting Information is available free of charge on the ACS Publications website at DOI: 10.1021/acscatal.6b01325.

NMR characterization, catalytic experiments, and computational details (PDF)

Crystallographic data (CIF)

\section{AUTHOR INFORMATION}

\section{Corresponding Authors}

*E-mail: luigi.cavallo@kaust.edu.sa (L. Cavallo).

*E-mail: alceo.macchioni@unipg.it (A. Macchioni).

Notes

The authors declare no competing financial interest.

\section{ACKNOWLEDGMENTS}

This work was financially supported by SABIC, Regione Umbria (POR FSE Projects), and COST Action CM1205 (CARISMA). We thank Prof. Antoni Llobet for helpful discussions and Dr. Stefano Giovagnoli for his help in performing DLS measurements.

\section{REFERENCES}

(1) Balzani, V.; Credi, A.; Venturi, M. ChemSusChem 2008, 1, 26-58.

(2) Young, K. J.; Martini, L. A.; Milot, R. L.; Snoeberger, R. C., III; Batista, V. S.; Schmuttenmaer, C. A.; Crabtree, R. H.; Brudvig, G. W. Coord. Chem. Rev. 2012, 256, 2503-2520.

(3) For molecular catalysts, see: (a) Molecular Water Oxidation, Llobet, A., Ed.; Wiley-Interscience: New York, 2014. (b) Kärkäs, M. D.; Verho, O.; Johnston, E. V.; Åkermark, B. Chem. Rev. 2014, 114, 11863-12001.

(4) For catalysts based on inorganic materials, see: Osterloh, F. E. Chem. Mater. 2008, 20, 35-54.

(5) Renger, G. Photosynth. Res. 2007, 92, 407-425.

(6) Parent, A. R.; Crabtree, R. H.; Brudvig, G. W. Chem. Soc. Rev. 2013, 42, 2247-2252.

(7) Rongé, J.; Bosserez, T.; Martel, D.; Nervi, C.; Boarino, L.; Taulelle, F.; Decher, G.; Bordiga, S.; Martens, J. A. Chem. Soc. Rev. 2014, 43, 7963-7981.

(8) Hara, M.; Waraksa, C. C.; Lean, J. T.; Lewis, B. A.; Mallouk, T. E. J. Phys. Chem. A 2000, 104, 5275-5280.

(9) Yoshida, M.; Masaoka, S.; Abe, J.; Sakai, K. Chem.—Asian J. 2010, 5, 2369-2378.

(10) Wasylenko, D. J.; Ganesamoorthy, C.; Henderson, M. A.; Berlinguette, C. P. Inorg. Chem. 2011, 50, 3662-3672.

(11) Kimoto, A.; Yamauchi, K.; Yoshida, M.; Masaoka, S.; Sakai, K. Chem. Commun. 2012, 48, 239-241.

(12) Stull, J. A.; Britt, R. D.; McHale, J. L.; Knorr, F. J.; Lymar, S. V.; Hurst, J. K. J. Am. Chem. Soc. 2012, 134, 19973-19976.

(13) Hetterscheid, D. G. H.; Reek, J. N. H. Eur. J. Inorg. Chem. 2014, 2014, 742-749.

(14) Yoshida, M.; Kondo, M.; Torii, S.; Sakai, K.; Masaoka, S. Angew. Chem., Int. Ed. 2015, 54, 7981-7984.

(15) Codolà, Z.; Gómez, L.; Kleespies, S. T.; Que, L., Jr.; Costas, M.; Lloret-Fillol, J. Nat. Commun. 2015, 6, 5865-5873.

(16) (a) Savini, A.; Bellachioma, G.; Ciancaleoni, G.; Zuccaccia, C.; Zuccaccia, D.; Macchioni, A. Chem. Commun. 2010, 46, 9218-9219. (b) Savini, A.; Belanzoni, P.; Bellachioma, G.; Zuccaccia, C.; Zuccaccia, D.; Macchioni, A. Green Chem. 2011, 13, 3360-3374. (c) Bucci, A.; Savini, A.; Rocchigiani, L.; Zuccaccia, C.; Rizzato, S.; Albinati, A.; Llobet, A.; Macchioni, A. Organometallics 2012, 31, 8071-8074. (d) Savini, A.; Bucci, A.; Bellachioma, A.; Giancola, S.; Palomba, F.; Rocchigiani, L.; Rossi, A.; Suriani, A.; Zuccaccia, C.; Macchioni, A. J. Organomet. Chem. 2014, 771, 24-32. (e) Corbucci, I.; Petronilho, A.; Müller-Bunz, H.; Rocchigiani, L.; Albrecht, M.; Macchioni, A. ACS Catal. 2015, 5, 2714-2718.

(17) Woods, J. A.; Bernhard, S.; Albrecht, M. In Molecular Water Oxidation, Llobet, A., Ed.; Wiley-Interscience: New York, 2014; pp $113-133$.

(18) Zuccaccia, C.; Bellachioma, G.; Bolaño, S.; Rocchigiani, L.; Savini, A.; Macchioni, A. Eur. J. Inorg. Chem. 2012, 2012, 1462-1468.

(19) Zuccaccia, C.; Bellachioma, G.; Bortolini, O.; Bucci, A.; Savini, A.; Macchioni, A. Chem.-Eur. J. 2014, 20, 3446-3456.

(20) Grotjahn, D. B.; Brown, D. B.; Martin, J. K.; Marelius, D. C.; Abadjian, M.-C.; Tran, H. N.; Kalyuzhny, G.; Vecchio, K. S.; Specht, Z. 
G.; Cortes-Llamas, S. A.; Miranda-Soto, V.; van Niekerk, C.; Moore, C. E.; Rheingold, A. L. J. Am. Chem. Soc. 2011, 133, 19024-19027.

(21) Koelewijn, J. M.; Lutz, M.; Dzik, W. I.; Detz, R. J.; Reek, J. N. H. ACS Catal. 2016, 6, 3418-3427.

(22) Hong, D.; Murakami, M.; Yamada, Y.; Fukuzumi, S. Energy Environ. Sci. 2012, 5, 5708-5716. Contrary to that found by Fukuzumi, DLS measurements (SI) did not afford any indication of the presence of nanoparticles.

(23) Samuni, A.; Czapski, G. J. Chem. Soc., Dalton Trans. 1973, 487488 and references therein..

(24) Wang, G.-C.; So, Y.-M.; Wong, K.-L.; Au-Yeung, K.-C.; Sung, H. H.-Y.; Williams, I. D.; Leung, W.-H. Chem.-Eur. J. 2015, 21, 1612616135.

(25) Pook, N.-P.; Adam, A. Z. Anorg. Allg. Chem. 2014, 640, 29312938.

(26) Wang, G.-C.; Sung, H. H. Y.; Williams, I. D.; Leung, W.-H. Inorg. Chem. 2012, 51, 3640-3647.

(27) Coles, M. P.; Hitchcock, P. B.; Khvostov, A. V.; Lappert, M. F.;

Li, Z.; Protchenko, A. V. Dalton Trans. 2010, 39, 6780-6788.

(28) Firouzabadi, H.; Iranpoor, N. Synth. Commun. 1984, 14, 875882.

(29) Firouzabadi, H.; Iranpoor, N.; Garzan, A. Adv. Synth. Catal. 2005, 347, 1925-1928.

(30) Paul, M.; Shirase, S.; Morimoto, Y.; Mathey, L.; Murugesapandian, B.; Tanaka, S.; Itoh, S.; Tsurugi, H.; Mashima, K. Chem.-Eur. J. 2016, 22, 4008-4014.

(31) Anandkumar, M.; Ramamurthy, C. H.; Thirunavukkarasu, C.; Babu, K. S. J. Mater. Sci. 2015, 50, 2522-2531 and references therein.. (32) (a) Petronilho, A.; Rahman, M.; Woods, J. A.; Al-Sayyed, H.; Müller-Bunz, H.; MacElroy, J. M. D.; Bernhard, S.; Albrecht, M. Dalton Trans. 2012, 41, 13074-13080. (b) Hintermair, U.; Sheehan, S. W.; Parent, A. R.; Ess, D. H.; Richens, D. T.; Vaccaro, P. H.; Brudvig, G. W.; Crabtree, R. H. J. Am. Chem. Soc. 2013, 135, 10837-10851. (c) Woods, J. A.; Lalrempuia, R.; Petronilho, A.; McDaniel, N. D.; Müller-Bunz, H.; Albrecht, M.; Bernhard, S. Energy Environ. Sci. 2014, 7, 2316-2328.

(33) Lewandowska-Andralojc, A.; Polyansky, D. E.; Wang, C.-H.; Wang, W.-H.; Himeda, Y.; Fujita, E. Phys. Chem. Chem. Phys. 2014, 16, 11976-11987.

(34) Savini, A.; Bucci, A.; Bellachioma, G.; Rocchigiani, L.; Zuccaccia, C.; Llobet, A.; Macchioni, A. Eur. J. Inorg. Chem. 2014, 2014, 690-697.

(35) For a recent paper dealing with cerium oxide cluster ions capable of releasing oxygen, see: Nagata, T.; Miyajima, K.; Mafuné, F. J. Phys. Chem. A 2015, 119, 1813-1819.

(36) Hintermair, U.; Hashmi, S. M.; Elimelech, M.; Crabtree, R. H. J. Am. Chem. Soc. 2012, 134, 9785-9795.

(37) Geometries were located with the Gaussian09 package at the BP86-D3 level, using the SDD ECP on Ir and Ce and the SVP basis set on all main group atoms. Energies were refined by single-point calculations at the M06 level with the TZVP basis set on main group atoms. Solvent effects were included with the PCM approach. Full details, coordinates, absolute energies, and $3 \mathrm{D}$ view of all the computed species can be found in the SI.

(38) Chen, Z.; Concepcion, J. J.; Hu, X.; Yang, W.; Hoertz, P. G.; Meyer, T. J. Proc. Natl. Acad. Sci. U. S. A. 2010, 107, 7225-7229.

(39) Concepcion, J. J.; Tsai, M.-K.; Muckerman, J. T.; Meyer, T. J. J. Am. Chem. Soc. 2010, 132, 1545-1557.

(40) Richmond, C. J.; Matheu, R.; Poater, A.; Falivene, L.; BenetBuchholz, J.; Sala, X.; Cavallo, L.; Llobet, A. Chem.-Eur. J. 2014, 20, 17282-17286.

(41) Blakemore, J. D.; Schley, N. D.; Balcells, D.; Hull, J. F.; Olack, G. W.; Incarvito, C. D.; Eisenstein, O.; Brudvig, G. W.; Crabtree, R. H. J. Am. Chem. Soc. 2010, 132, 16017-16029. 